\title{
In Vitro Antiallergic Activity of Flavonoids in Histamine Release Assay Using Rat Basophilic Leukemia (RBL-2H3) Cells
}

(Received April 15, 1994)

\author{
Masaru KaWASAKI*1, *2, Masatake Toyoda*1, Reiko Teshima*1, \\ Jun-ichi SawadA*1, Toshimitsu Hayashi ${ }^{* 3}$, Munehisa ARISAwA ${ }^{* 3}$, \\ Mineo Shimizu*3, Naokata Morita*3, Syozo Inoue*4 \\ and Yukio SAITo*1 \\ (*1 National Institute of Health Sciences: 1-18-1, Kamiyoga, Setagaya-ku, Tokyo 158, Japan; \\ *2Present address: Hatano Research Institute, Food and Drug Safety Center: 729-5, \\ Ochiai, Hadano-shi, Kanagawa 257, Japan, To whom reprint requests should \\ be addressed; ${ }^{* 3}$ Faculty of Pharmaceutical Sciences, Toyama Medical \& \\ Pharmaceutical University: 2630, Sugitani, Toyama 930-01, Japan; \\ ${ }^{*}$ Nitto Denko Co.: 1-1-2, Shimohozumi, Ibaraki, \\ Osaka 567, Japan)
}

\begin{abstract}
We used an established cell line, rat basophilic leukemia cells (RBL-2H3) to screen 40 flavonoids for inhibitory activity on antigen-induced histamine release from immunogloblin $\mathrm{E}$ (IgE)-sensitized RBL-2H3 cells. To exclude non-specific inhibition, the cytotoxicity to RBL$2 \mathrm{H} 3$ cells was simultaneously determined. Flavonoid aglycones showed a stronger activity for histamine release-inhibition and cytotoxicity than glycosides, and both activities were almost in parallel. Baicalein showed histamine release-inhibitory activity with the $\mathrm{IC}_{50}$ of $1.07 \times 10^{-5}$ $M$ in this bioassay system. However, it showed a potent cytotoxicity $\left(\mathrm{IC}_{50} 9.62 \times 10^{-6} M\right)$. On the other hand, scutellarein ( $4^{\prime}$-hydroxybaicalein) showed a potent histamine releaseinhibitory activity $\left(\mathrm{IC}_{50} 3.15 \times 10^{-6} \mathrm{M}\right)$ and low cytotoxicity $\left(\mathrm{IC}_{50} 6.11 \times 10^{-5} \mathrm{M}\right)$. We found that scutellarein has a potent histamine release-inhibitory activity and low cytotoxicity.
\end{abstract}

Key words: rat basophilic leukemia cell; antiallergy; histamine release-inhibitor; cytotoxicity; flavonoide; scutellarein

\section{Introduction}

Flavonoids, a large group of naturally occurring pigments, are widely distributed in the plant kingdom and also are major components in some edible plants. Certain flavonoids inhibit various enzymes, such as phosphodiesterase ${ }^{3 / \sim 5 \text { ), }}$ $\mathrm{Ca}^{2+}-\mathrm{ATPase}^{6)}$, aldose reductase ${ }^{7) \sim 9)}$, lipoxygenase ${ }^{10,11)}$, cyclooxygenase and xanthine oxidase $^{12}$. Several flavonoids have a histamine release-inhibitory activity on rat peritoneal mast cells $^{13) \sim 15}$. However, comparative studies on the antiallergic activity of many kinds of flavonoids have not yet been done. The release of inflammatory mediators, such as histamine and leukotrienes, from mast cell or basophils, is med- iated by cell-surface receptors for immunoglobulin $\mathrm{E}$ ( $\mathrm{IgE}$ ), and stimulation by antigen results in allergic reactions called immediate-type hypersensitivity. In vitro antiallergic screening has generally been performed by using rat peritoneal mast cells, but a disadvantage of this method is that mast cells must be prepared from experimental animals before each assay. Rat basophilic leukemia cells (RBL-2H3) release histamine, serotonin and $\beta$-hexosaminidase when exposed to various stimuli in vitro ${ }^{1)}$. The antigen-induced histamine release from $\operatorname{IgE}$ sensitized RBL-2H3 cells provides an in vitro model for in vivo antigen-induced allergic reactions. Since RBL-2H3 is an established cell line and easy to subculture, antiallergic screening 
assay using this cell line should be rapid and reproducible. In this paper we describe a bioassay system using RBL-2H3 cells to screen histamine-release inhibitors among 40 flavonoids. Cytotoxic activity was simultaneously determined to find substances which show a strong inhibitory effect on histamine release from RBL$2 \mathrm{H} 3$ cells combined with low cytotoxicity.

\section{Materials and Methods}

\section{Cells and medium}

RBL-2H3 cells (JCRB 0023) were obtained from the Japan Cancer Research Resources Bank. The medium used for cell culture was Eagle's minimum essential medium (MEM; Kohjin Bio Co. Ltd.) supplemented with 10\% fetal calf serum (FCS, GIBCO Co. Ltd.) and 0.08 $\mathrm{mg} / \mathrm{ml}$ kanamycin (Nakarai Co.). Monoclonal $\operatorname{IgE}$ antibody-producing hybridoma (IGELa2) was purchased from ATCC (TIB 142).

\section{Buffer}

The following buffer was used: $140 \mathrm{mM} \mathrm{NaCl}$, $5 \mathrm{~m} M \mathrm{KCl}, 0.6 \mathrm{mM} \mathrm{MgCl} 2,1.0 \mathrm{~m} M \mathrm{CaCl}_{2}, 5.5 \mathrm{~m} M$ glucose, $0.1 \%$ bovine serum albumin (BSA), and $5 \mathrm{~m} M \quad n$-2-(hydroxyethyl) piperazine- $N^{\prime}$-2-ethanesulfonic acid (HEPES), pH 7.4.

\section{Antigen (DNP $P_{T} B S A$ ) and monoclonal IgE antibody}

Dinitrophenylated BSA was prepared by dinitrophenylation of BSA with 2,4-dinitrobenzenesulfonic acid. The extent of dinitrophenylation was $7 \mathrm{~mol}$ per mole of BSA. Monoclonal mouse $\operatorname{IgE}$ antibody specific for the 2,4dinitrophenyl group was prepared by using IGELa2 ${ }^{16)}$ cells. The cells were propagated in vivo in pristane-treated $\mathrm{BALB} / \mathrm{c}$ mice, and the ascites was used as anti-TNP IgE.

\section{Flavonoids}

We isolated and identified most of the flavonoids from plant sources. Most of the flavonoids listed in Table 2 were the same samples as those reported by Hayashi et al. ${ }^{12}$. All flavonoids were dissolved in DMSO and the solution was diluted in medium, so that the concentration of DMSO in the medium was under $0.2 \%$. This concentration of DMSO did not interfere with the bioassay or analysis of histamine.
Measurement of histamine release-inhibitory activity

Measurement of histamine release-inhibitory activity was performed by the method of Teshima et $a l .{ }^{2)}$ with a slight modification. RBL-2H 3 cells $\left(1 \times 10^{5}\right.$ cells $/$ well $)$ were plated in 24 -well flat-bottomed microtiter plates (Costar 3424) in $0.5 \mathrm{ml}$ per well of MEM containing $10 \%$ FCS and incubated for $24 \mathrm{hr}$ at $37^{\circ} \mathrm{C}$. The supernatants were discarded, and the cells were incubated at $37^{\circ} \mathrm{C}$ for $120 \mathrm{~min}$ with $0.5 \mathrm{ml}$ of MEM containing 2\% FCS and TNP-specific monoclonal IgE antibody (1000-fold-diluted ascites). Then the supernatants were removed and the cells were washed three times with the buffer to remove unbound IgE. After incubation at $37^{\circ} \mathrm{C}$ for $10 \mathrm{~min}$ with a flavonoid-containing buffer $(0.4 \mathrm{ml})$, the cells were challenged with $100 \mu \mathrm{l}$ of DNP-BSA ( $100 \mu \mathrm{g} / \mathrm{ml}$ of the buffer) for $35 \mathrm{~min}$ at $37^{\circ} \mathrm{C}$. Cold HEPES buffer $(600 \mu \mathrm{l})$ was added to stop the reaction. One $\mathrm{ml}$ of the supernatant was withdrawn from each well and mixed with $20 \mu 1$ of perchloric acid. The supernatant was centrifuged at $12,000 \mathrm{rpm}$ for $30 \mathrm{~min}$ at $2^{\circ} \mathrm{C}$ and then filtered through a $2 \mu \mathrm{m}$ Millipore filter. The filtrates were submitted to HPLC. Histamine release-inhibitory activities (\% inhibition) were calculated as follows: \% Inhibition $=100 \times\{1-$ $[(\mathrm{SR}-\mathrm{SC}) /(\mathrm{T}-\mathrm{SC})] /[(\mathrm{R}-\mathrm{C}) /(\mathrm{T}-\mathrm{C})]\}$, where $\mathrm{T}$ is the mean of total histamine content determined by adding perchloric acid (2\% final concentration) to the same sample; $\mathrm{C}$ is the histamine content spontaneously released from control cells; $\mathrm{SC}$ is the histamine content spontaneously released from flavonoid-treated cells; $\mathrm{R}$ is the histamine content released from control cells by antigen stimulation; SR is the histamine content released from flavonoid-treated cells by antigen stimulation. The $\mathrm{IC}_{50}$ was determined as the $50 \%$ inhibitory concentration compared to the control by plotting the inhibition data as dose-effect curves (Fig. 2), from which the 50\%-inhibitory concentration was calculated.

\section{Measurement of histamine content of medium}

Released histamine was measured by a Shimadzu histamine analysis system based on the HPLC method of Somehara et al., ${ }^{17)}$ using post column derivatization with ortho-phthalaldehyde (OPA). Figure 1 shows a schematic flow 
diagram of the system and analytical conditions.

\section{Cytotoxicity}

RBL-2H3 cells were plated in 24-well flat- bottomed microtiter plates (Costar 3424) in 0.5 $\mathrm{ml}$ of MEM containing $10 \%$ FCS per well and incubated for $72 \mathrm{hr}$ at $37^{\circ} \mathrm{C}$ in the presence of flavonoid. The medium was removed, the cell monolayers were trypsinized, and the viable cell

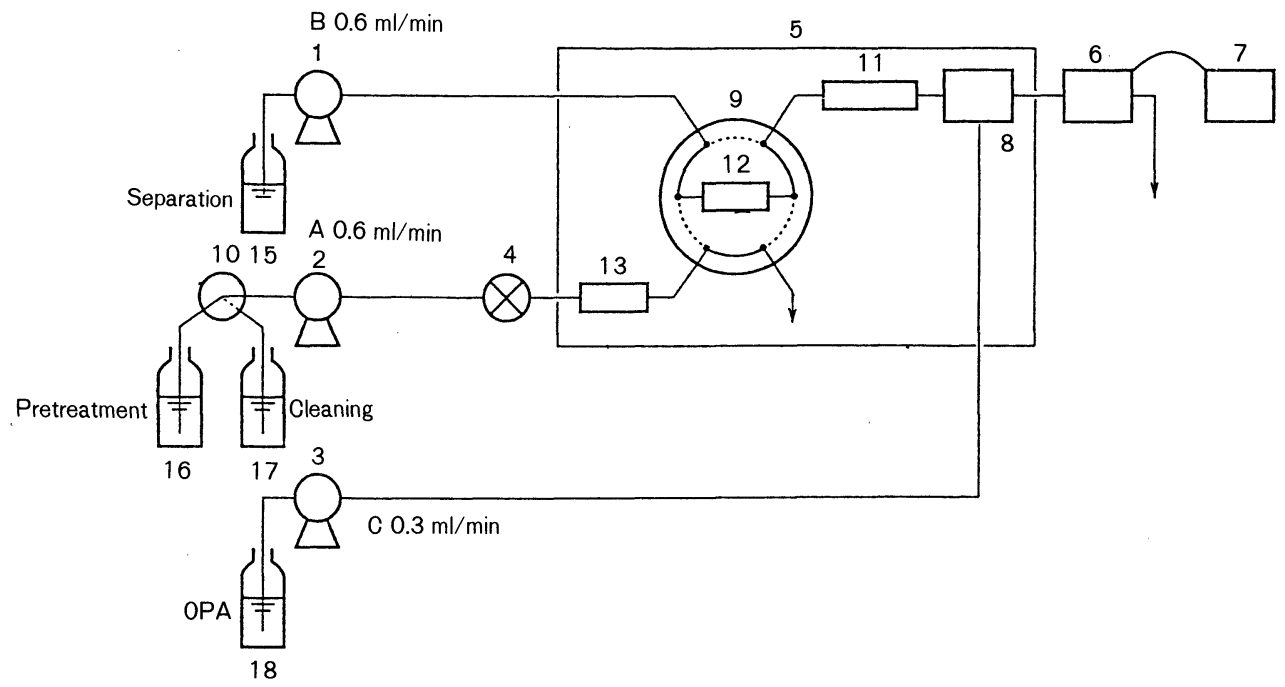

Apparatus: 1, 2, 3; pumps, 4; injector, 5; oven, 6; detector, 7; data processor, 8; reactor, 9; valve, 10; valve, 11; analytical column, 12; trap column, 13; pre-column, 15, 16, 17; mobile phase, 18; reagent

Analytical conditions

[For separation]

Column Shim-pack PAG-SP $(10 \mathrm{~mm} \times 8 \mathrm{~mm} \varnothing)$ for pretreatment Shim-pack ISC-05 (10 $\mathrm{mm} \times 4 \mathrm{~mm} \varnothing)$ for trapping Shim-pack ISC-05 (38 $\mathrm{mm} \times 4.6 \mathrm{~mm}$ ) for separation

Mobile phase $100 \mathrm{mM}$ (sodium) EDTA $<\mathrm{pH}=6.0>$ containing $10 \mathrm{~m} M$ sodium dodecylsulfate for pretreatment $100 \mathrm{~m} M$ (sodium) EDTA $<\mathrm{pH}=8.5>$ containing $1 M$ sodium perchlorate for separation

Flow rate $100 \mathrm{mM}$ (sodium) EDT $<\mathrm{pH}=8.5>$ for cleaning

Temperature $0.6 \mathrm{ml} / \mathrm{min}$

Programming $50^{\circ} \mathrm{C}$

trap column into analytical line at $3.3 \mathrm{~min}$ trap column into pretreatment line at $7 \mathrm{~min}$

[For detection]

Reagent

1\% OPA acetonitrile solution and $4 \mathrm{mM}$ sodium dihydrogenphosphate dihydrate $<\mathrm{pH}$ $=2.8>$ aqueous solution $(1: 20 \mathrm{v} / \mathrm{v})$

Flow rate $0.3 \mathrm{ml} / \mathrm{min}$

Reactor

Temperature piping part $\mathrm{J}(400 \mu \mathrm{l})$

Detection $50^{\circ} \mathrm{C}$ fluorescence at $E x=360 \mathrm{~nm} ; E m=440 \mathrm{~nm}$

[Sample]

Injection volume $100 \mu 1$

Fig. 1. Schematic flow diagram of the Shimadzu histamine analysis system and analytical conditions 

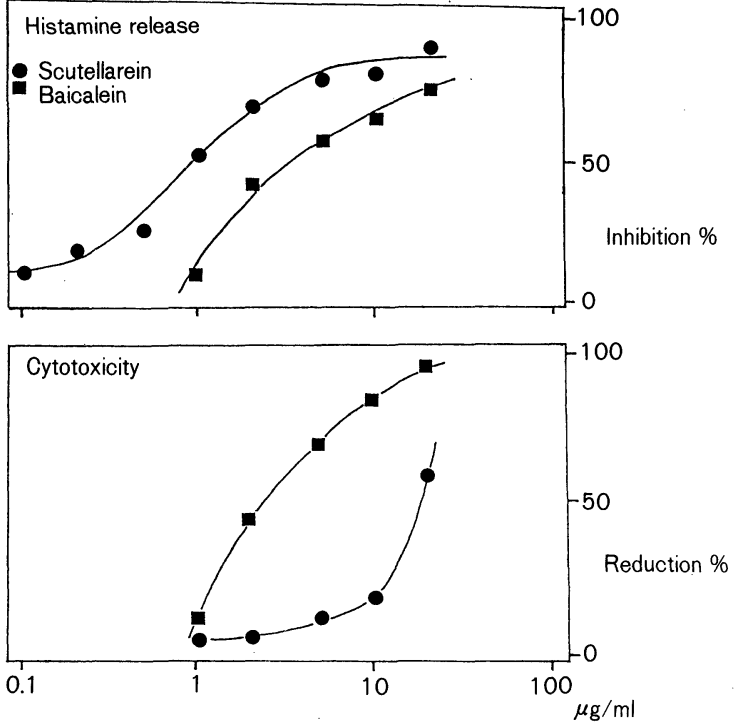

Fig. 2. Cytotoxicity and inhibitory effects of scutellarein and baicalein on histamine release from RBL-2H3 cells number was determined by a trypan blue dye exclusion method. Cytotoxicity (\% inhibition) was calculated as follows: \% inhibition $=100 \times$ $[1-(\%$ viable cell in flavonoid-treated cells $) /(\%$ viable cell in drug-untreated cells)]

\section{Results and Discussion}

\section{Bio-assay}

RBL-2H3 cells sensitized with anti-TNP IgE were preincubated with each test substance for $10 \mathrm{~min}$. Then, the cells were stimulated by the antigen, DNP-BSA. In this assay, ketotifen fumarate salt, which is an antiallergic compound, showed a histamine release-inhibitory activity with an $\mathrm{IC}_{50}$ value of $8.46 \times 10^{-5} \mathrm{M}$. It has been reported that RBL-2H3 cells have a similar function to that of mucosal-type mast cells as regards type I allergic reaction ${ }^{18)}{ }^{19}$.

\section{Antiallergic effect and cytotoxicity of flavonoids}

The inhibitory activities of 40 flavonoids against histamine release and their cytotoxicity at

Table 1. Histamine Release-Inhibitory Activity and Cytotoxicity of Flavonols and Their Derivatives

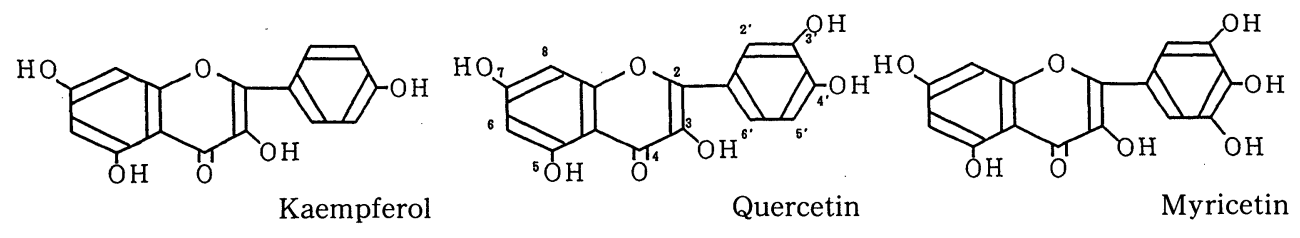

\begin{tabular}{|c|c|c|c|c|}
\hline & \multicolumn{2}{|c|}{ Inhibition of histamine release } & \multicolumn{2}{|c|}{ Cytotoxicity } \\
\hline & $\begin{array}{l}\text { Inhibition \% } \\
(20 \mu \mathrm{g} / \mathrm{ml})\end{array}$ & $\mathrm{IC}_{50}(M)$ & $\begin{array}{l}\text { Inhibition \% } \\
(20 \mu \mathrm{g} / \mathrm{ml})\end{array}$ & $\mathrm{IC}_{50}(M)$ \\
\hline Kaempferol & 84.0 & $1.25 \times 10^{-5}$ & 66.0 & - \\
\hline Quercetin & 84.3 & $2.05 \times 10^{-5}$ & 85.0 & $4.13 \times 10^{-5}$ \\
\hline Myricetin & 59.9 & - & 16.7 & - \\
\hline 3-O-Methyl quercetin & 74.2 & - & 80.0 & $3.80 \times 10^{-6}$ \\
\hline $3^{\prime}$-O-Methyl quercetin & 65.2 & - & 70.0 & $6.30 \times 10^{-5}$ \\
\hline Quercetin 3-O-glucuronide & 36.2 & - & 10.0 & - \\
\hline Quercetin 3-O-glucoside & 5.2 & - & 29.6 & - \\
\hline Quercetin 3-O-rhamnoside & 40.7 & - & 0.0 & - \\
\hline Quercetin 3-O-galactoside & 61.6 & - & 25.0 & - \\
\hline Quercetin 3-O-arabinofuranoside & 53.5 & - & 25.0 & - \\
\hline Quercetin 3-O-rutinoside & 36.2 & - & 5.0 & - \\
\hline Quercetin 3-O-glucoside $2^{\prime \prime}$-O-gallate & 16.8 & - & 5.0 & - \\
\hline Quercetin $3^{\prime}-O$-methyl-4'-O-glucoside & 24.3 & - & 81.5 & $1.40 \times 10^{-6}$ \\
\hline Myricetin 3-O-rhamnosylgalactoside & 71.4 & - & 7.4 & - \\
\hline Myricetin 3-O-rhamnoside & 51.6 & - & 0.0 & - \\
\hline Myricetin 3-O-arabinoside & 36.0 & - & 3.7 & - \\
\hline
\end{tabular}

一: Not tested 
$20 \mu \mathrm{g} / \mathrm{ml}$ were measured. The dose-response curves of two potent inhibitory flavonoids (baicalein and scutellalein) are shown in Fig. 2. Both flavonoids had almost maximum histaminerelease inhibitory activity at the dosage of 20 $\mu \mathrm{g} / \mathrm{ml}$. Therefore, we chose concentration of 20 $\mu \mathrm{g} / \mathrm{ml}$ as a screening concentration. The values of $\%$ inhibition are listed in Tables $1 \sim 3 . \mathrm{IC}_{50}$ 's (50\% inhibitory concentration) were determined when flavonoids showed more than $75 \%$ inhibition at $20 \mu \mathrm{g} / \mathrm{ml}$. Flavonoid aglycones appeared to show a stronger histamine release-inhibitory activity and cytotoxicity than glycosides, and both activities were almost in parallel.

\section{Flavonols}

The data for flavonols are presented in Table 1. Histamine release-inhibitory activity was observed with kaempferol $\left(\mathrm{IC}_{50} 1.25 \times 10^{-5} M\right)$ and quercetin $\left(\mathrm{IC}_{50} 2.05 \times 10^{-5} \mathrm{M}\right)$. Similar inhibitory activity has been reported against antigeninduced histamine release of human basophils. $^{20), 21)}$. Quercetin 3-methyl ether and 3'. methyl ether exhibited cytotoxicity but did not

Table 2. Histamine Release-Inhibitory Activity and Cytotoxicity of Flavones and Their Glycosides in RBL-2H3 Cells Induced with TNP-IgE and DNP-BSA<smiles>[R16]c1cc(-c2cc(=O)c3c([R])c([R])c([R])c([R])c3o2)cc([R])c1[R4]</smiles><smiles>O=c1cc(-c2ccc(O)cc2)oc2cc(O)c(O)c(O)c12</smiles>

Scutellarein

\begin{tabular}{|c|c|c|c|c|c|c|c|c|c|c|c|}
\hline & \multicolumn{7}{|c|}{ Substituents } & \multicolumn{2}{|c|}{$\begin{array}{c}\text { Inhibition of } \\
\text { histamine release }\end{array}$} & \multicolumn{2}{|c|}{ Cytotoxicity } \\
\hline & $\mathrm{R}_{5}$ & $\mathrm{R}_{6}$ & $\mathrm{R}_{7}$ & $\mathrm{R}_{8}$ & $\mathrm{R}_{3^{\prime}}$ & $\mathrm{R}_{4^{\prime}}$ & $\mathrm{R}_{5^{\prime}}$ & $\begin{array}{l}\text { Inhibition \% } \\
(20 \mu \mathrm{g} / \mathrm{ml})\end{array}$ & $\begin{array}{l}\mathrm{IC}_{50} \\
(M)\end{array}$ & $\begin{array}{l}\text { Inhibition \% } \\
(20 \mu \mathrm{g} / \mathrm{ml})\end{array}$ & $\begin{array}{l}\mathrm{IC}_{50} \\
(M)\end{array}$ \\
\hline Apigenin & $\mathrm{OH}$ & $\mathrm{H}$ & $\mathrm{OH}$ & $\mathrm{H}$ & $\mathrm{H}$ & $\mathrm{OH}$ & $\mathrm{H}$ & 85.9 & $8.88 \times 10^{-6}$ & 100.0 & $2.22 \times 10^{-5}$ \\
\hline Luteolin & $\mathrm{OH}$ & $\mathrm{H}$ & $\mathrm{OH}$ & $\mathrm{H}$ & $\mathrm{OH}$ & $\mathrm{OH}$ & $\mathrm{H}$ & 92.2 & $1.75 \times 10^{-5}$ & 100.0 & $2.73 \times 10^{-5}$ \\
\hline $\begin{array}{l}\text { Apigenin } 7-O- \\
\text { glucuronide }\end{array}$ & $\mathrm{OH}$ & $\mathrm{H}$ & $\mathrm{R}_{1}$ & $\mathrm{H}$ & $\mathrm{H}$ & $\mathrm{OH}$ & $\mathrm{H}$ & 9.0 & - & 11.1 & - \\
\hline $\begin{array}{l}\text { Luteolin } 7-O- \\
\text { glucoside }\end{array}$ & $\mathrm{OH}$ & $\mathrm{H}$ & $\mathrm{R}_{2}$ & $\mathrm{H}$ & $\mathrm{OH}$ & $\mathrm{OH}$ & $\mathrm{H}$ & 29.9 & - & 18.5 & - \\
\hline Baicalein & $\mathrm{OH}$ & $\mathrm{OH}$ & $\mathrm{OH} \cdot$ & $\mathrm{H}$ & $\mathrm{H}$ & $\mathrm{H}$ & $\mathrm{H}$ & 89.6 & $1.07 \times 10^{-5}$ & 73.4 & $9.62 \times 10^{-6}$ \\
\hline Baicalein- $\mathrm{Me}_{3}$ & $\mathrm{OMe}$ & $\mathrm{OMe}$ & $\mathrm{OMe}$ & $\mathrm{H}$ & $\mathrm{H}$ & $\mathrm{H}$ & $\mathrm{H}$ & 55.3 & - & -4.0 & - \\
\hline Scutellarein & $\mathrm{OH}$ & $\mathrm{OH}$ & $\mathrm{OH}$ & $\mathrm{H}$ & $\mathrm{H}$ & $\mathrm{OH}$ & $\mathrm{H}$ & 99.5 & $3.15 \times 10^{-6}$ & 77.1 & $6.11 \times 10^{-5}$ \\
\hline $\begin{array}{l}\text { Scutellarein } 4^{\prime} \text {-methyl } \\
\text { ether }\end{array}$ & $\mathrm{OH}$ & $\mathrm{OH}$ & $\mathrm{OH}$ & $\mathrm{H}$ & $\mathrm{H}$ & $\mathrm{OMe}$ & $\mathrm{H}$ & 75.5 & $4.70 \times 10^{-5}$ & 49.1 & $6.71 \times 10^{-5}$ \\
\hline Scutellarin & $\mathrm{OH}$ & $\mathrm{OH}$ & $\mathrm{OR}_{1}$ & $\mathrm{H}$ & $\mathrm{H}$ & $\mathrm{OH}$ & $\mathrm{H}$ & 18.8 & - & 50.0 & - \\
\hline Pectrinarigenin & $\mathrm{OH}$ & $\mathrm{OMe}$ & $\mathrm{OH}$ & $\mathrm{H}$ & $\mathrm{H}$ & $\mathrm{OMe}$ & $\mathrm{H}$ & 94.6 & $2.61 \times 10^{-5}$ & 92.0 & $1.34 \times 10^{-5}$ \\
\hline Sorbifolin & $\mathrm{OH}$ & $\mathrm{OH}$ & $\mathrm{OMe}$ & $\mathrm{H}$ & $\mathrm{H}$ & $\mathrm{OH}$ & $\mathrm{H}$ & 98.5 & $6.30 \times 10^{-6}$ & 98.1 & $7.30 \times 10^{-6}$ \\
\hline $\begin{array}{c}\text { Scutellarein } 5,6,4^{\prime}- \\
\text { trimethyl ether }\end{array}$ & $\mathrm{OMe}$ & $\mathrm{OMe}$ & $\mathrm{OH}$ & $\mathrm{H}$ & $\mathrm{H}$ & $\mathrm{OMe}$ & $\mathrm{H}$ & 58.5 & - & 18.9 & - \\
\hline Cirsimaritin & $\mathrm{OH}$ & $\mathrm{OMe}$ & $\mathrm{OMe}$ & $\mathrm{H}$ & $\mathrm{H}$ & $\mathrm{OH}$ & $\mathrm{H}$ & 85.5 & $1.05 \times 10^{-5}$ & 45.8 & $6.37 \times 10^{-5}$ \\
\hline $\begin{array}{l}\text { Scutellarein } 4^{\prime}, 6,7,- \\
\text { trimethyl ether }\end{array}$ & $\mathrm{OH}$ & $\mathrm{OMe}$ & $\mathrm{OMe}$ & $\mathrm{H}$ & $\mathrm{H}$ & $\mathrm{OMe}$ & $\mathrm{H}$ & 50.1 & - & 20.8 & - \\
\hline Cirșimarin & $\mathrm{OH}$ & $\mathrm{OMe}$ & $\mathrm{OMe}$ & $\mathrm{H}$ & $\mathrm{H}$ & $\mathrm{OR}_{2}$ & $\mathrm{H}$ & -11.6 & - & 94.0 & $2.00 \times 10^{-5}$ \\
\hline Pectrinarin & $\mathrm{OH}$ & $\mathrm{OMe}$ & $\mathrm{OR}_{3}$ & $\mathrm{H}$ & $\mathrm{H}$ & $\mathrm{OMe}$ & $\mathrm{H}$ & 15.5 & - & 12.0 & - \\
\hline Sinesetin & $\mathrm{OMe}$ & $\mathrm{OMe}$ & $\mathrm{OMe}$ & $\mathrm{H}$ & $\mathrm{OMe}$ & $\mathrm{OMe}$ & $\mathrm{H}$ & 21.5 & - & 15.1 & - \\
\hline $\begin{array}{l}5,6,7,8,4^{\prime} \text {-penta-OH } \\
\quad \text { flavone }\end{array}$ & $\mathrm{OH}$ & $\mathrm{OH}$ & $\mathrm{OH}$ & $\mathrm{OH}$ & $\mathrm{H}$ & $\mathrm{OH}$ & $\mathrm{H}$ & 13.9 & - & 11.3 & - \\
\hline $\begin{array}{l}5,6,7,3^{\prime}, 4^{\prime}, 5^{\prime}-\text { Hexame- } \\
\text { thoxyflavone }\end{array}$ & $\mathrm{OMe}$ & $\mathrm{OMe}$ & $\mathrm{OMe}$ & $\mathrm{H}$ & $\mathrm{OMe}$ & $\mathrm{OMe}$ & $\mathrm{OMe}$ & 41.3 & - & 5.6 & - \\
\hline
\end{tabular}

—: Not tested; $\mathrm{R}_{1}$ : Glucuronide; $\mathrm{R}_{2}$ : Glucoside; $\mathrm{R}_{3}$ : Rhamnosylglucoside 
Table 3. Histamine Release-Inhibitory Activity and Cytotoxicity of C-Glycosylated Flavones and Their Derivatives<smiles>[R]c1ccc(-c2cc(=O)c3c(O)c([R])c([R])c([R])c3o2)cc1[R]</smiles>

\begin{tabular}{|c|c|c|c|c|c|c|c|c|c|}
\hline & \multicolumn{5}{|c|}{ Substituents } & \multicolumn{2}{|c|}{$\begin{array}{c}\text { Inhibition of } \\
\text { histamine release }\end{array}$} & \multicolumn{2}{|c|}{ Cytotoxicity } \\
\hline & $\mathrm{R}_{6}$ & $\mathrm{R}_{7}$ & $\mathrm{R}_{8}$ & $\mathrm{R}_{3^{\prime}}$ & $\mathrm{R}_{4^{\prime}}$ & $\begin{array}{c}\text { Inhibition \% } \\
(20 \mu \mathrm{g} / \mathrm{ml})\end{array}$ & $\begin{array}{l}\mathrm{IC}_{50} \\
(M)\end{array}$ & $\begin{array}{l}\text { Inhibition \% } \\
(20 \mu \mathrm{g} / \mathrm{ml})\end{array}$ & $\begin{array}{l}\mathrm{IC}_{50} \\
(M)\end{array}$ \\
\hline Vitexin & $\mathrm{H}$ & $\mathrm{OH}$ & Glc- & $\mathrm{H}$ & $\mathrm{OH}$ & 16.0 & - & 19.5 & - \\
\hline Swertisin & Glc- & $\mathrm{MeO}$ & $\mathrm{H}$ & $\mathrm{H}$ & $\mathrm{OH}$ & 8.1 & - & 2.9 & - \\
\hline Embinin & Rhm-O-Glu- & $\mathrm{OH}$ & $\mathrm{H}$ & $\mathrm{H}$ & $\mathrm{OMe}$ & 40.8 & - & 0.0 & - \\
\hline iso-Orientin & Glc- & $\mathrm{OH}$ & $\mathrm{H}$ & $\mathrm{OH}$ & $\mathrm{OH}$ & 5.8 & - & 4.1 & - \\
\hline iso-Orientin 7 -O-glucoside & Glc- & Glc-O- & $\mathrm{H}$ & $\mathrm{OH}$ & $\mathrm{OH}$ & 30.0 & - & 29.5 & - \\
\hline
\end{tabular}

—: Not tested; Glc: Glucose; Rhm: Rhamnose

have strong inhibitory activity on histamine release. Quercetin and myricetin glycosides did not show either activity. It seems that flavonols require a 3-OH group for inhibitory activity, and a 3-O-glycoside group may sterically hinder the active site of the aglycone.

\section{Flavones}

Histamine release-inhibitory activity and cytotoxicity of flavones are summarized in Table 2. Both apigenin and luteolin have histamine release-inhibitory activity and cytotoxicity. Baicalein, a well known antiallergic flavonoid ${ }^{14), 15)}$, showed histamine releaseinhibitory activity with the $\mathrm{IC}_{50}$ of $1.07 \times 10^{-5} \mathrm{M}$ in this bio-assay system. However, it showed a potent cytotoxicity $\left(\mathrm{IC}_{50} 9.62 \times 10^{-6} M\right)$. On the other hand, scutellarein (4'-hydroxybaicalein) showed a potent histamine release-inhibitory activity $\left(\mathrm{IC}_{50} 3.15 \times 10^{-6} \mathrm{M}\right)$ and low cytotoxicity $\left(\mathrm{IC}_{50} 6.11 \times 10^{-5} M\right.$ ) (Fig. 1). Glycosides of the 7 position of baicalein and scutellarein have low histamine release-inhibitory activity. Moreover, histamine release-inhibitory activity was observed in scutellarein $4^{\prime}$-methyl ether, pectrinarigenin, sorbifolin and cirsimaritin (Table 2).

Scutellarein $\left(4^{\prime}-\mathrm{OH}\right)$ has a stronger inhibitory activity (more than one order) than baicalein $\left(4^{\prime}-\mathrm{H}\right)$, but scutellarein $4^{\prime}$-methyl ether is about one order less active. A similar phenomenon was observed with pectrinaigenin $\left(4^{\prime}-\mathrm{OMe}\right) v s$. sorbiforin $\left(4^{\prime}-\mathrm{OH}\right)$. These findings suggest that a free hydroxyl group at the $\mathrm{C}-4^{\prime}$ position in the B-ring increases the histamine release-inhibitory activity and substitution or absence of the free C- 4 ' hydroxyl group decreases the activity. Flavonoids methoxylated (more than two) in the A-ring or glycosylated in the A-ring are less active. 5,6,7,8,4'-pentahydroxyflavone has a lower activity, possibly because this paraquinone-type flavonoid is easily decomposed.

Middeleton et al. ${ }^{20), 21)}$ revealed critical structure-activity relationships governing the flavonoid effect on antigen-induced histamine release from human basophils. Inhibitory activity was associated with the presence of the C4-keto5 -OH couplet and was enhanced by the additional presence of the $\mathrm{C} 3-\mathrm{OH}$ group and an appropriate pattern of hydroxylation in the B-ring. Lim asset et $a{ }^{2}{ }^{22)}$ have also examined the effect of flavonoids on the release of reactive oxygen species from stimulated human neutrophils. They affirmed the importance of A-ring $(5-\mathrm{OH}$, 7-OH) and B-ring $\left(3^{\prime}-\mathrm{OH}, 4^{\prime}-\mathrm{OH}\right)$ dihydroxylation and C-ring $(3-\mathrm{OH})$ hydroxylation. This potency is generally decreased by glycosylation. Thus, $5-\mathrm{OH}$ and free hydroxy groups in the A- or Bring are important for activity. In our screening assay, all histamine release-inhibitory flavonoids had a free-OH group at the $\mathrm{C}-5$ position. Histamine release-inhibitory activity of baicalein-type flavonoids required the aglycone, a free 
5-hydroxyl group, and a 6- or 7-hydroxyl group, and furthermore, the presence of a $4^{\prime}$-hydroxyl group enhanced the activity.

\section{C-Glycosylated flavone}

C-Glycosylated flavonoids (listed in Table 3) were less active.

\section{Acknowledgment}

We are indebted to Dr. Yutaka Kikuchi, National Institute of Health Sciences, for suggesting the use of cultured RBL-2H3.

\section{References}

1) Kataoka, M., Takagaki, Y.: Shoyakugaku Zasshi 46, 25 29 (1992).

2) Teshima, R., Ikebuchi, H., Sekita, S., Natori, S., Terao, T.: Int. Archs. Allergy Appl: Immun. 78, 237 242 (1985).

3) Ruckstul, M., Beretz, A., Anton, R., Landry, Y.: Biochem. Pharmacol. 28, 535 538 (1979).

4) Petkov, E., Nikolv, N., Uzunov, P.: Planta Med. 43, 183 (1981).

5) Nikaido, T., Ohmoto, T., Nomura, T., Fukai, T., Sankawa, U.: Chem. Pharm. Bull. 32, 4,929 4,934 (1984).

6) Fewtrel, C. M. S., Gomperts, B. D.: Nature 265, 635 636 (1977).

7) Varma, S. D., Kinoshita, J. H.: Biochem. Pharmacol., 25 2,505 2,513 (1976).

8) Okuda, J., Miwa, I., Inagaki, K., Horie, T., Nakayama, M.: Chem. Pharm. Bull. 32, 767 772 (1984).

9) Shimizu, M., Ito, T., Terashima, S., Hayashi, T.,
Arisawa, M., Morita, N., Kurokawa, S., Ito, K., Hashimoto Y.: Phytochemistry 23, 1,885 1,889 (1984).

10) Sekiya, S., Okuda, H.,: Biochem. Biophy.s. Res. Commun. 105, 1,090 (1982).

11) Yoshimoto, T., Furukawa, M., Yamamoto, S., Horie, T., Watanabe, K.: ibid. 116, 612 616 (1983).

12) Hayashi, T., Sawa, K., Kawasaki, M., Arisawa, M., Shimizu, M., Morita, N.: J. Natural Products 51, 345 348 (1988).

13) Ohtsuka, H., Hirai, Y., Nagao, T., Yamasaki, K.: ibid. 66, 237 (1970).

14) Koda, A., Nagai, H., Wada, H.: Folia Pharmacol. Japan. 66, 194 213 (1970).

15) Koda, A.: Iyakuhin no Kaihatsu p. $466 \sim 480$ (1989), Hirokawa-shoten, Tokyo.

16) Rudolph, A. K., Burrows, P. D., Wabl, M. R.: Eur. J. Immunol, 11, 527 529 (1981).

17) Somehara, T., Hayashi, M., Egi, S.: Annual Meeting of Japan Analytical Chemistry Society p. 235 238 (1988)

18) Barusumian, E. L., Isersky, C., Petrino, M. G., Siraganian, R. P.: Eur. J. Immunol. 11, 317 323 (1981).

19) Metzger, H., Alcaraz, G., Hohman, R., Kinet, J. P., Pribludo, U., Quarto, R.: Annu. Rev. Immunol. 4, 419 470 (1986)

20) Middeleton, E. Jr., Drezewiecki, G.: Biochem. Pharmacol. 31, 1,449 1,453 ( 1982).

21) Middeleton, E. Jr., Kandaswami, C.: ibid. 43 1,167 1,179 ( 1992)

22) Limasset, B., Douchen, C., Dore, J.-C., Ojasoo, T., Damon, M., Paulet, A. C.: ibid. 46, 1,257 1,271 (1993). 